\title{
The Role of Interleukin-converting Enzyme in Fas-mediated Apoptosis in HIV-1 Infection
}

\author{
Elaine M. Sloand, ${ }^{\star}$ Jaroslaw P. Maciejewski, ${ }^{\S}$ Tadatsugu Sato, ${ }^{\star}$ Jennifer Bruny, ${ }^{\star}$ Princy Kumar, ${ }^{\ddagger}$ Sonnie Kim, ${ }^{\star}$ \\ Frank F. Weichold, $\|$ and Neal S. Young* \\ *Hematology Branch, National Heart, Lung, and Blood Institute, Bethesda, Maryland 20892; ${ }^{\ddagger}$ Georgetown University Medical Center, \\ Washington, District of Columbia 20007; ${ }^{\S}$ Department of Internal Medicine, University of Nevada, School of Medicine, Reno, Nevada \\ 89557; and Institute of Human Virology, University of Maryland, Baltimore, Maryland 21201
}

\begin{abstract}
Apoptosis of $\mathrm{CD}^{+}$lymphocytes is partially responsible for the depletion of these cells in HIV-infected individuals. $\mathrm{CD}^{+}$lymphocytes from $\mathrm{HIV}-1-$ infected patients express higher membrane levels of the Fas receptor, and are particularly susceptible to apoptosis after Fas triggering. IL-1 $\beta-$ converting enzyme (ICE) is a key enzyme of the apoptotic machinery involved in Fas-mediated apoptosis of normal lymphocytes. The role of ICE in mediating the increased susceptibility of $\mathrm{CD}^{+}$lymphocytes from HIV-1-infected patients to apoptosis has not been examined. In this study, we found that ICE mRNA was present in T cells from both HIV-1-infected patients and controls. Active ICE proteins, p10 and p20, were demonstrated by immunoblot in lymphocytes from HIV-1-infected patients and in normal lymphocytes after treatment with Fas agonist, CH11 mAb. Cocultivation of lymphocytes from HIV-1-infected persons with Fas antagonist, antibody ZB4, resulted in decreased expression of ICE protein in lymphocytes from HIV-infected patients, and decreased apoptosis. Similar effects were obtained when cells were treated with synthetic ICE inhibitors, which blocked apoptosis in response to Fas triggering. When $\mathrm{CD}^{+}$and $\mathrm{CD}^{+}$cells were sorted by flow cytometry and analyzed by reverse transcriptase PCR, ICE mRNA was present in both $\mathrm{CD}^{+}$and $\mathrm{CD}^{+}$cells. However, flow cytometric analysis of lymphocytes with intracellular staining for ICE demonstrated ICE protein in the $\mathrm{CD}^{+}$but not the $\mathrm{CD}^{+}$cell fraction derived from blood of $\mathrm{HIV}-1$-infected patients. These data suggest that activation of ICE occurs in vivo in $\mathrm{CD}^{+}$lymphocytes from HIV-1-infected individuals, and may account for the increased susceptibility of $\mathrm{CD}^{+}{ }^{+}$cells to apoptosis. (J. Clin. Invest. 1998. 101:195-201.) Key words: interleukin-converting enzyme • Fas • apoptosis • HIV • AIDS
\end{abstract}

\section{Introduction}

Infection with HIV-1 is associated with profound depletion of $\mathrm{CD} 4^{+}$cells, at least partially accounted for by apoptosis (1-3),

\footnotetext{
Address correspondence to Elaine Sloand, M.D., National Heart, Lung, and Blood Institute, National Institutes of Health, Building 31, Room 4A11, 31 Center Drive MSC 2490, Bethesda, MD 20892-2490. Phone: 301-496-3245; FAX: 301-594-1290; E-mail: sloande@gwgate. nhlbi.nih.gov

Received for publication 30 April 1997 and accepted in revised form 16 October 1997.
}

The Journal of Clinical Investigation

Volume 101, Number 1, January 1998, 195-201

http://www.jci.org a process that is associated with an enhanced expression and subsequent triggering of the Fas receptor (Fas-R) ${ }^{1}$ (4-7). Apoptosis can be mediated by cross-linking of the Fas-R by either soluble or membrane-bound Fas ligand (Fas-L), and we have previously demonstrated increased levels of soluble and cellassociated Fas-L expression on lymphocytes of HIV-1-infected patients (5). Despite substantial work in this area, factors governing selective apoptosis and depletion of $\mathrm{CD}^{+}$cells are still unknown. Although the Fas- $\mathrm{R}$ is upregulated on both $\mathrm{CD}^{+}$ and $\mathrm{CD}^{+}$lymphocytes from patients with AIDS, $\mathrm{CD} 4^{+}$cells are selectively sensitive to Fas-mediated apoptosis (5).

Cross-linking of Fas-R leads to activation of an array of cysteine proteases (caspases) in a cascade-like fashion (8-13). The active form of interleukin-converting enzyme (ICE), or caspase- 1 , is produced in this process $(8,10)$. ICE activates IL$1 \beta$, a proinflammatory lymphokine, and indirectly inactivates poly(ADP) ribose polymerase, an enzyme used in DNA repair $(14,15)$. Overexpression of ICE results in apoptosis. Generation of oxygen and nitrogen radicals has also been associated with apoptosis, and may be activated after stimulation with TNF- $\alpha$, IFN- $\gamma$, or Fas-R agonists $(16,17)$. Recent studies have shown that Fas-mediated apoptosis of $\mathrm{CD}^{+}$cells could be blocked by specific inhibitors of ICE, suggesting that ICE may also be important in the regulation of $\mathrm{CD}^{+}$cell apoptosis in HIV-1 infection (18).

In this study, we attempted to determine the role of ICE in the apoptotic mechanism operating in $\mathrm{CD}^{+}$cells in HIV-1 infection. We investigated the nature of the relationship between Fas-R triggering and ICE activation, and determined whether inhibition of ICE activity in lymphocytes derived from HIV-1-infected patients results in increased $\mathrm{CD}^{+}{ }^{+}$survival by blocking apoptosis.

\section{Methods}

Patients. Peripheral blood (PB) samples were obtained from patients with AIDS and from normal volunteers after obtaining informed consent according to protocols approved by the Institutional Review Board of the National Heart, Lung, and Blood Institute and the Georgetown University Medical Center. PB samples were obtained from 116 patients with HIV-1 infection, and 40 normal volunteers. Among HIV-1-infected patients, 80 had CD4 counts $<200$, 71 had a history of at least one opportunistic infection, and 100 have been treated with antiviral agents, including ddC, AZT, or a combination. A group of 40 normal uninfected blood donors were used as controls. Cell separation and culture. PBMC were separated using density gradient centrifugation with lymphocyte separation media (Organon Teknika, Durham, NC). Thereafter, cells were washed twice with

1. Abbreviations used in this paper: Fas-L, Fas ligand; Fas-R, Fas receptor; ICE, interleukin-converting enzyme; PB, peripheral blood; PE, phycoerythrin; RT-PCR, reverse transcriptase PCR. 
PBS and resuspended in RPMI 1640 supplemented with FCS (both from Life Technologies, Inc., Gaithersburg, MD). Cultures were performed at a cell density of $0.5 \times 10^{6}$ cells $/ \mathrm{ml}$. When appropriate, natural lymphocyte-derived IL-2 (Boehringer Mannheim Biochemicals, Indianapolis, IN) or PHA (Boehringer Mannheim Biochemicals) were used for stimulation at concentrations of $10 \mathrm{U} / \mathrm{ml}$ or $5 \mu \mathrm{g} / \mathrm{ml}$, respectively. Anti-Fas mAb CH11 (Kamyia, San Francisco, CA), an antibody that mimics the Fas-L by cross-linking the Fas-R, or ZB4, a blocking anti-Fas mAb (Amac, Inc., Westbrook, ME), were used at $1 \mu \mathrm{g} / \mathrm{ml}$.

Cell viability assays. Cell viability was measured using a standard Trypan blue (Life Technologies, Inc.) exclusion test or an automated colorimetric assay using the tetrazolium bromide (MTT) reduction reaction. The blue formazan product was assayed spectrophotometrically based on a standard curve and correlated to Trypan blue exclusion results.

Flow cytometry. For the measurement of Fas expression on $\mathrm{CD}^{+}{ }^{+}$and $\mathrm{CD} 8^{+}$PBMC by flow cytometry, a whole blood test was used. Briefly, $100 \mu \mathrm{l}$ of blood was incubated with $20 \mu \mathrm{l}$ phycoerythrin (PE)-conjugated anti-CD4 or -CD8 mAb (Becton Dickinson, Mountain View, CA) combined with $20 \mu$ of FITC-conjugated anti-CD95 mAb (UB2, PharMingen, San Diego, CA). After 30 min of incubation, erythrocytes were lysed with $0.12 \%$ formic acid, and the remaining cells were washed and fixed in $0.2 \%$ paraformaldehyde using the Q-prep reagent system (Coulter Corp., Hialeah, FL). Samples were analyzed using a flow cytometer (Epics ELITE; Coulter Corp.). In some experiments, density gradient-purified cells or cultured PBMC were analyzed. Cells were incubated in a volume of $100 \mu \mathrm{l}$ with the appropriate $\mathrm{mAb}$, washed twice with PBS, and fixed with paraformaldehyde. For sorting, PBMC were stained with either anti-CD4 or anti-CD8 $\mathrm{mAb}$, washed, and separated with the flow cytometer. The purity of sorted cells was routinely $95-98 \%$. Intracellular staining for ICE expression was carried out using an intracellular staining kit (PharMingen) (19).

Apoptosis assay. PBMC were prepared as described above, washed with PBS, and stained with annexin and propidium iodide as described previously (20). Samples were analyzed using flow cytometry.

Western blot analysis. For immunoblotting, similar numbers of PBMC obtained from HIV-1-infected individuals and normal controls were cultured without antibodies as described previously for $72 \mathrm{~h}$. Cells were subsequently pelleted, and the supernatant was applied to a $100-\mathrm{kD}$ filter to remove fragments. For analysis of Fas-L, plasma samples were also concentrated using a $3-\mathrm{kD}$ filter before analysis. For analysis of ICE, cells were solubilized in 3\% SDS. Supernatants and cells were electrophoresed in $12 \%$ SDS-polyacrylamide gels, equilibrated in transfer buffer $(125 \mathrm{mmol} / \mathrm{liter}$ Tris-base, $960 \mathrm{mmol} /$ liter glycine, $20 \%$ methanol), and separated proteins were transferred electrophoretically on polyvinylidene difluoride membranes (Immobilon-P; Millipore Corp., Bedford, MA). Membranes were blocked in TBST-milk (10 mmol/liter Tris-HCl [pH 8.0], 150 $\mathrm{mmol} /$ liter $\mathrm{NaCl}, 0.5 \%$ Tween $20,1 \%$ nonfat dry milk, $1 \%$ BSA [Cohn fraction V; Miles Inc., Kankakee, IL]) and treated with rabbit anti-Fas-L (an antibody to the amino terminal of Fas-L) (Santa Cruz Biotechnology, Inc., Santa Cruz, CA) at room temperature. For ICE immunoblotting, a pan-ICE antibody was used (Amersham Corp., Arlington Heights, IL). After washing three times in TBST-milk, the membranes were incubated with alkaline phosphatase-labeled goat anti-rabbit IgG (1:2,000 dilution) at room temperature and subsequently with mouse antialkaline phosphatase mAb (DAKO Corp., Carpinteria, CA). Specific bands were detected using nitro blue tetrazolium/5-bromo-4 chloro-3-indolyl phosphate substrate (Pierce Chemical Co., Rockford, IL). Immunoprecipitation was performed using lysed PBMC, and ICE antibody cell lysates were analyzed on 14\% PAGE and stained with silver stain (Novex, San Diego, CA). Densitometry was performed on the dried gel using a densitometer (Hoefer Scientific Instruments, San Francisco, CA).

Reverse transcriptase PCR (RT-PCR) for detection of ICE expres- sion. Total RNA was extracted from constant numbers of purified CD34 ${ }^{+}$cells using RNAsol (Cinna/Biotecx, Friendswood, TX). Contaminating DNA was digested using RNAse-free DNAse I (Boehringer Mannheim Biochemicals). RNA was reextracted with phenol/ chloroform, precipitated with ethanol, and diluted in RNAse-free water. After reverse transcription using an oligo $d(T)_{16}$ primer, ICE cDNA was amplified using the primer pair 5'-GGTCCTGAAGGAGAAGAGAA-3' and 5'-AGGCCTGGATGATGATCACC-3' specific for human ICE mRNA. For the amplification reaction, reagents supplied in the Amplimer kit (Perkin-Elmer Corp., Foster City, CA) were used. The following reverse transcription and amplification conditions were used: $45 \mathrm{~min}$ at $37^{\circ} \mathrm{C}$, and $5 \mathrm{~min}$ at $96^{\circ} \mathrm{C}$ for the reverse transcription reaction, and 30 cycles of $2 \mathrm{~min}$ at $96^{\circ} \mathrm{C}, 1.5 \mathrm{~min}$ at $55^{\circ} \mathrm{C}$, and $2 \mathrm{~min}$ at $72^{\circ} \mathrm{C}$ for amplification. PCR products were electrophoresed in $1.2 \%$ agarose gels. The bands were visualized after staining with ethidium bromide and ultraviolet light exposure.

Statistical analysis. The percentage of Fas-expressing cells was calculated by dividing the number of $\mathrm{CD}^{+} / \mathrm{CD}^{+}$cells binding $\mathrm{mAb}$ $\mathrm{CD} 95$ by the total number of $\mathrm{CD}^{+} / \mathrm{CD}^{+}$cells. Statistical significance was calculated using a nonparametric Wilcoxon two-sample or one-sample test.

\section{Results}

Differential expression of ICE in PBMC from HIV-1-infected patients and normal donors. We first studied expression of ICE in PBMC derived from HIV-1-infected patients and normal controls. A group of $40 \mathrm{HIV}-1-$ infected patients with advanced disease was selected for our study. Clinical characteristics are listed in Table I. When RT-PCR was performed on mononuclear cells from these patients and from normal blood donors using ICE-specific primers, ICE mRNA could be detected in both controls and HIV-1-infected patients (Fig. 1).

We then studied the expression of ICE protein in normal and HIV-1-infected individuals. Western blot, in addition to providing a semiquantitative measure for ICE protein expression, also distinguishes between the active (p10 and p20) and precursor forms ( $\mathrm{p} 45$ ) of ICE. When equal numbers of PBMC obtained from HIV-1-infected and uninfected individuals were analyzed by Western blot and stained with anti-ICE antibody, lymphocyte lysates from all patients but not from controls demonstrated protein bands of 10 and $20 \mathrm{kD}$, described previously as active ICE proteins (21) (Fig. 2). Three of four asymptomatic patients taking protease inhibitors did not exhibit ICE protein. Although patients with higher CD4 cell counts appeared to demonstrate less ICE protein, the number of pa-

\section{Table I. Characteristics of HIV-infected Patients Evaluated}

Patients receiving antiviral therapy

Nucleoside reverse transcriptase inhibitors $\quad 71 \%$

Protease inhibitors*

$13 \%$

Nonnucleoside reverse transcriptase inhibitors $\quad 5 \%$

None

$8 \%$

Active opportunistic infection at time of evaluation

Cryptococcus

$2 \%$

Cytomegalovirus retinitis

$8 \%$

Average CD4 count

171

*All but one patient were receiving protease inhibitors for $<2$ mo before the study. 2 of 40 patients were receiving cytotoxic chemotherapy for Kaposi's sarcoma. 
HIV $+\quad$ NORMAL

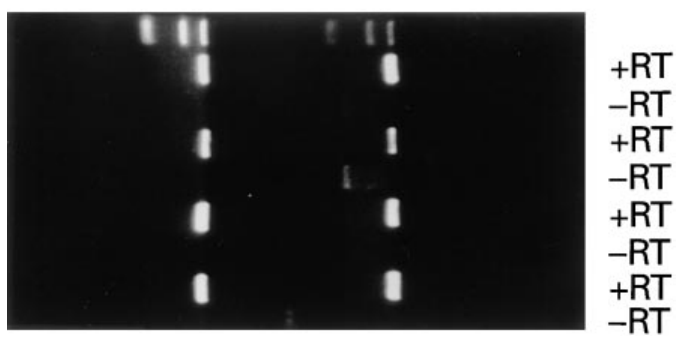

Figure 1. Expression of ICE mRNA in PBMC of HIV-1-infected patients. mRNA derived from mononuclear cells of HIV-1-infected patients and normal blood donors were analyzed by RT-PCR. Agarose gel electrophoresis of RT-PCR products after staining with ethidium bromide is seen. Bands indicate the ICE-specific amplification products.

tients with high CD4 counts $(>250$ cells $/ \mathrm{ml})$ was too low to show statistical significance.

Addition of Fas antagonist (mAb ZB4) to lymphocyte cultures derived from HIV-1-infected patients resulted in decreases in the expression of active ICE proteins as determined by immunoblot (Fig. 3). However, culture of normal PBMC in the presence of Fas agonist, mAb $\mathrm{CH} 11$, resulted in production of active ICE proteins by normal PBMC (Fig. 3).

A

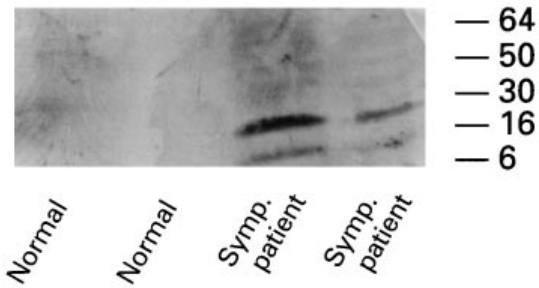

B

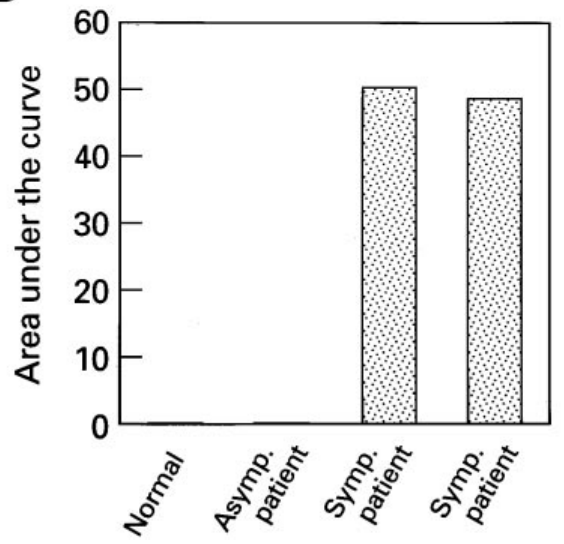

Figure 2. Expression of active ICE proteins $\mathrm{p} 10$ and p20 in symptomatic HIV-infected patients not receiving protease inhibitors. $(A) \mathrm{Im}$ munoblots of cell lysates derived from HIV-infected (Symp.) patients. (B) Immunoprecipitation of proteins from lysed PBMC. PBMC from normal uninfected controls and symptomatic (Symp.) and asymptomatic (Asymp.) HIV-infected patients were immunoprecipitated with anti-ICE antibodies, stained with silver stain, and scanned with a densitometer. Bars, area under the curve after scanning.

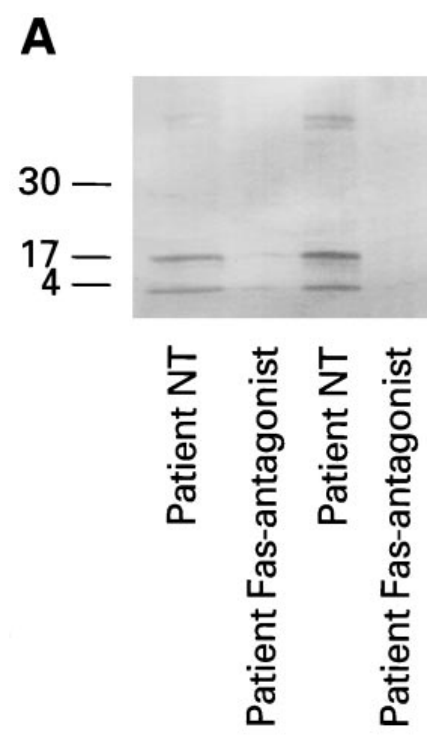

B

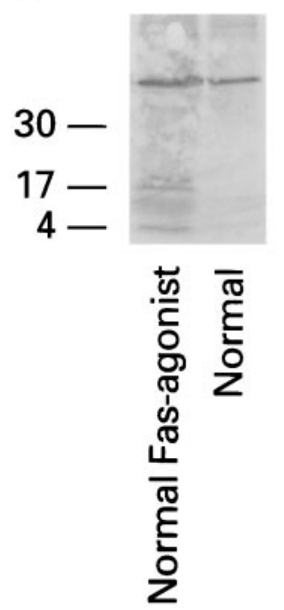

Figure 3. Effects of Fas-R stimulation and blockade on ICE protein expression. $(A)$ Immunoblots of patients lysed PBMC performed with anti-ICE antibodies. PBMC from $\mathrm{HIV}$-infected patients were cultured overnight without (control) or with Fas antagonist, ZB4 mAb. Active ICE proteins could be demonstrated in untreated $(N T)$ patients' cells (control), whereas decreased ICE expression could be demonstrated when these PBMC were cocultivated with Fas antagonist. $(B)$ PBMC from normal uninfected controls were cultured overnight without (control) or with Fas agonist, CH11. Increased levels of ICE proteins could be demonstrated in cells treated with Fas agonist but not in untreated samples (controls).

Differential expression of ICE in $C D 4^{+}$and $C D 8^{+}$lymphocytes. In patients with HIV-1 infection, $\mathrm{CD} 4^{+}$cells selectively undergo apoptosis. When $\mathrm{CD}^{+}$and $\mathrm{CD}^{+}$cells from HIV-1infected individuals were permeabilized and analyzed by flow cytometry after staining with either CD4 or CD8 mAb and anti-ICE antibodies, ICE proteins were seen predominantly in $\mathrm{CD}^{+}$cells but not $\mathrm{CD}^{+}$cells (Fig. 4). Examples of scattergrams of $\mathrm{CD}^{+}$and $\mathrm{CD}^{+}$cells are seen in Figs. 5 and 6. Normal lymphocytes did not express ICE protein as measured by flow cytometry. To determine if this differential expression of ICE protein was associated with decreased ICE mRNA in $\mathrm{CD}^{+}$cells, we stained lymphocytes from patients with HIV infection with CD4-CyPE and CD8-PE mAb, sorted them, and performed RT-PCR. Both $\mathrm{CD}^{+}$and $\mathrm{CD} 8^{+}$cell fractions could be demonstrated to contain ICE mRNA (Fig. 7); the relative amounts of ICE mRNA were not determined.

Fas-R has been shown to be an important mediator of lymphocyte apoptosis in HIV-1 infection. As ICE is involved in the mechanisms of Fas-mediated apoptosis, we investigated whether ICE and Fas (CD95) expression coincide. As demonstrated using triple-color fluorescent staining and flow cytome- 


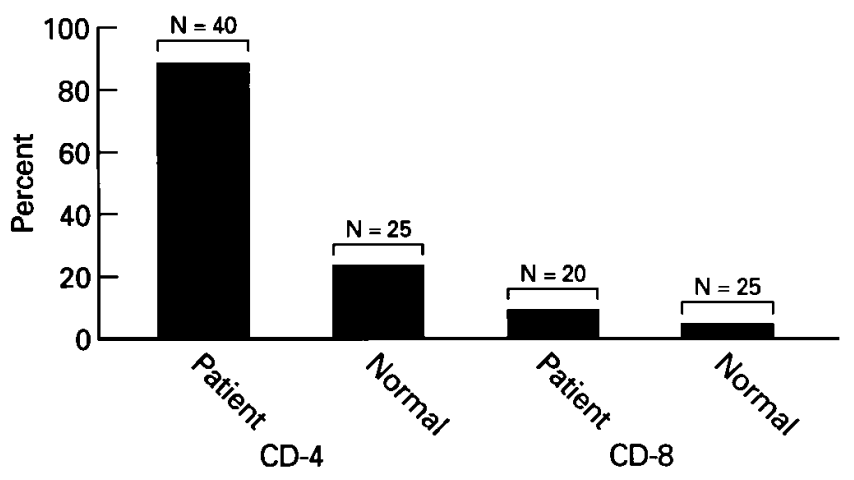

Figure 4. ICE expression in $\mathrm{CD}^{+}$and $\mathrm{CD} 8^{+}$cells from $\mathrm{HIV}$-infected patients. Lymphocytes from HIV-1-infected patients and normal uninfected donors were reacted with CD4-PE or CD8-PE, then fixed, permeabilized, and stained with anti-ICE antibody. Bars, Percentages of cells expressing ICE by flow cytometry.

try, most $\mathrm{CD}^{+}$cells reacting with ICE antibodies also expressed the Fas-R (Fig. 8).

Suppression of apoptosis by ICE inhibitors. To determine whether ICE is involved in Fas-mediated apoptosis, we used synthetic inhibitors of ICE. Blockade of ICE should result in inhibition of Fas-mediated apoptosis. When mononuclear cell cultures derived from HIV $-1^{+}$patients were supplemented with Fas agonist, $\mathrm{CH} 11$, lymphocytes underwent apoptosis as evidenced by annexin staining, which is indicative of early apoptosis. ICE inhibitor, Ac-Tyr-Val-Ala-Asp-aldehyde, both blocked completely loss of cell viability and prevented apoptosis (Fig. 9) in both untreated and PHA-supplemented cultures of PBL obtained from HIV-infected patients. In cultures of normal lymphocytes, which show low rates of spontaneous

\section{Normals}

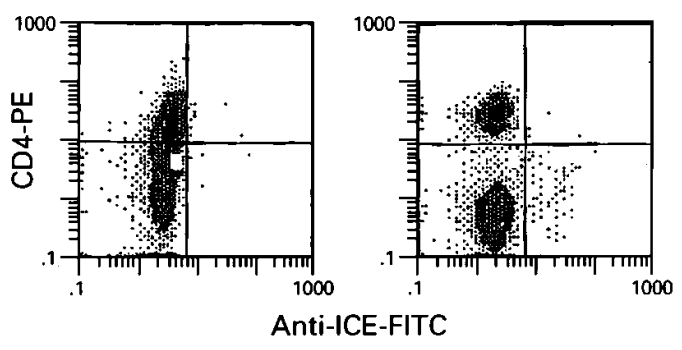

Patients

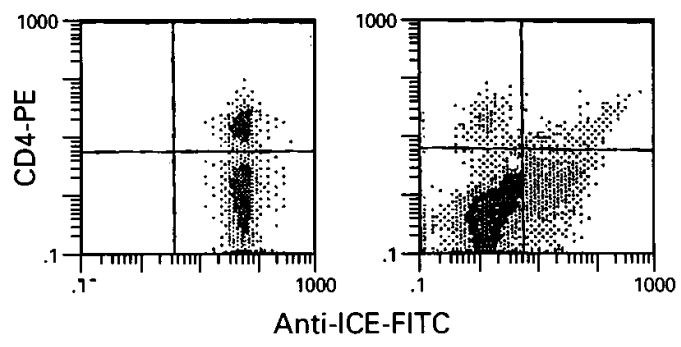

Figure 5. ICE expression in $\mathrm{CD}^{+}$cells as measured by flow cytometry. Example of a scattergram of $\mathrm{CD}^{+}$cells stained with CD4-PE and anti-ICE FITC.

\section{Normals}

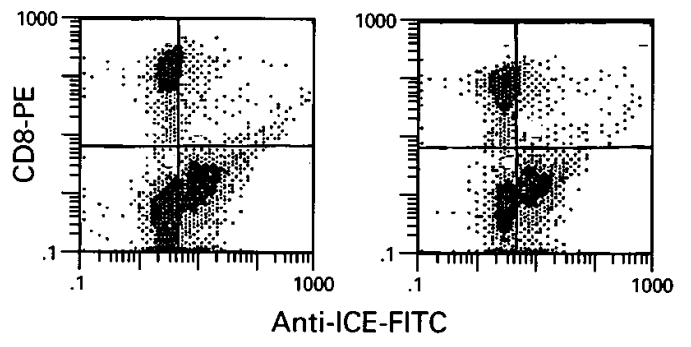

Patients

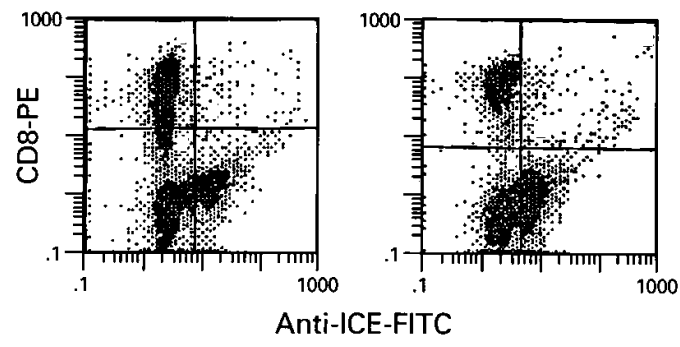

Figure 6. Flow cytometric analysis of ICE expression in CD8 ${ }^{+}$cells. Example of a scattergram of $\mathrm{CD}^{+}$cells stained with CD4-PE and anti-ICE FITC.

apoptosis, the effects of ICE inhibitors were less pronounced (data not shown). Previously, we demonstrated that Fas agonists decreased HIV replication in HIV-infected lymphocytes (5). We tested the effects of ICE inhibition on this phenomenon. We did not demonstrate any effect of ICE inhibitors on HIV-1 replication in lymphocytes treated with Fas agonist, CH11 antibody, but were only able to detect p24 antigen in three of five cultures tested (data not shown).

\section{Discussion}

Apoptosis and marked depletion of $\mathrm{CD}^{+}$lymphocytes in HIV-1 infection are fundamental elements in the pathophysiology of AIDS. Previous studies have demonstrated that Fasmediated apoptosis plays an important role in these processes in HIV-1 infection (5-7). Upregulation and triggering of Fas-R cannot alone account for the destruction of $\mathrm{CD} 4^{+}$lymphocytes, as increased Fas- $\mathrm{R}$ expression is also seen on $\mathrm{CD} 8^{+}$cells, and $\mathrm{CD} 4^{+}$cells appear to be much more sensitive to Fas-mediated apoptosis than $\mathrm{CD}^{+}$cells $(5,6)$.

In this study, we demonstrated that lymphocytes from HIV-1-infected patients expressed much higher levels of active ICE protein than those derived from normal individuals. Expression of ICE protein was decreased by Fas antagonists (mAb ZB4), whereas Fas agonist, mAb CH11, greatly enhanced ICE expression in normal lymphocytes. Our results clearly demonstrate that although ICE mRNA was detected in both $\mathrm{CD}^{+}$and $\mathrm{CD}^{+}$cells, ICE protein expression was predominant in $\mathrm{CD}^{+}$cells, and $\mathrm{CD}^{+}$cells showed only low levels of ICE protein. These findings are consistent with observations that $\mathrm{CD}^{+}$lymphocytes of HIV-1-infected patients are highly sensitive to Fas-induced apoptosis $(5,7)$. Cocultivation of lymphocytes with ICE inhibitors resulted in decreased spontaneous and Fas-mediated apoptosis in lymphocytes from 

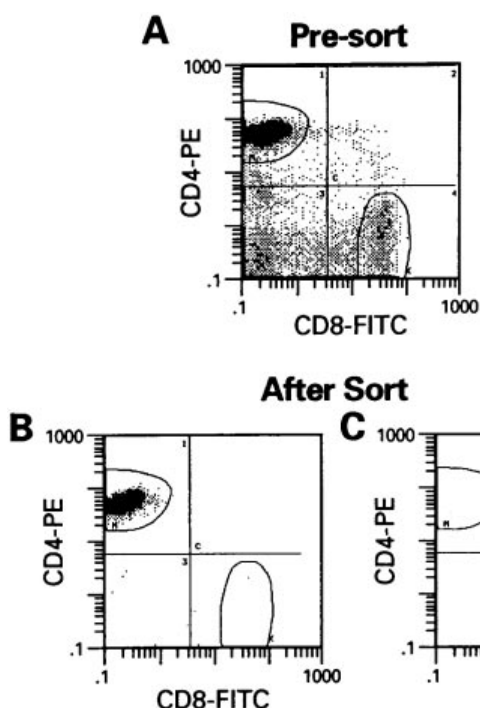

After Sort
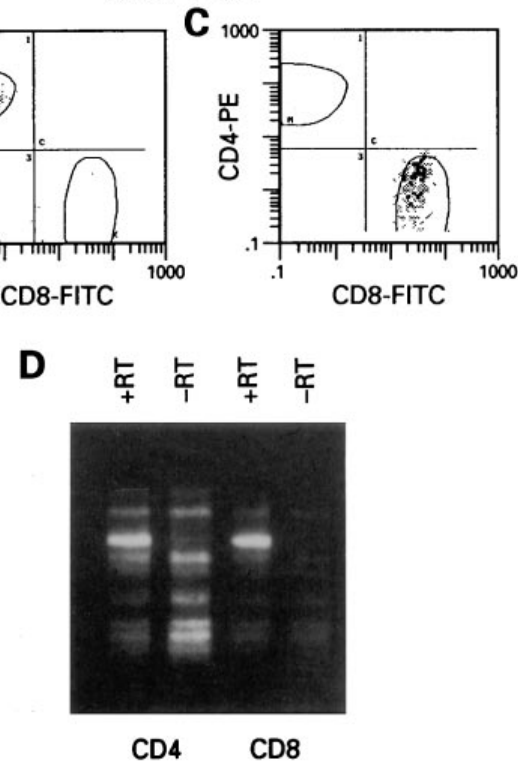

Figure 7. Analysis of ICE mRNA expression in $\mathrm{CD}^{+}$from samples of PBMC derived from HIV-infected patients were stained with CD4-CyPE and CD8-PE and sorted, and RT-PCR was performed using RNA derived from either $\mathrm{CD} 4^{+}$or $\mathrm{CD} 8^{+}$lymphocytes. Agarose electrophoresis of RT-PCR products after staining with ethidium bromide is seen $(D)$. Bands indicate ICE-specific amplification products. DNA contamination is evident in lane 2. $A-C$ demonstrate scattergrams obtained by flow cytometry pre- and postsorting.

HIV-1-infected individuals. The effects of ICE inhibitors were less pronounced in normal lymphocytes, which express lower levels of Fas-R and active ICE protein. These results suggested that ICE plays a key role in the induction of apoptosis in $\mathrm{CD}^{+}$ cells of patients with HIV-1 infection. Our finding that annexin staining, which recognizes membrane phosphatidylserine, was blocked by ICE inhibitors is consistent with others' reports demonstrating that externalization of phosphatidylserine occurred after ICE activation (22).

Regulation of ICE protein expression in lymphocytes may occur at either the pre- or posttranscriptional level. Although we demonstrated that ICE mRNA was present in both $\mathrm{CD}^{+}$ and $\mathrm{CD}^{+}$cells, it should be kept in mind that RT-PCR does not quantify the amount of mRNA in the cell. In addition, the pan-ICE antibody used for identification of the ICE protein both for flow cytometry and immunoblotting, although recognizing active ICE proteins $\mathrm{p} 10$ and p20, did not bind reliably to a pro-ICE $45-\mathrm{kD}$ protein weight on immunoblot, i.e., it appeared to be specific mainly for active ICE proteins. There still remains the possibility that the site of regulation of the ICE protein is at the point of activation of the pro-ICE protein, and most evidence in other cell lines suggest this.
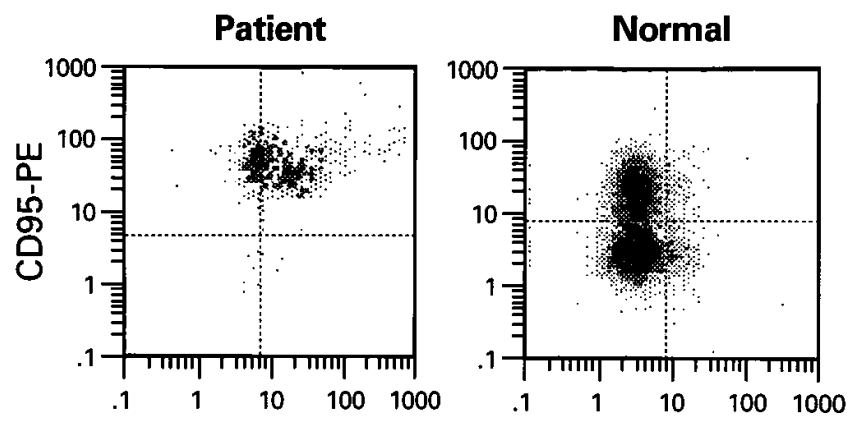

\section{Anti-ICE-FITC}

Figure 8. Flow cytometric analysis of ICE protein expression in $\mathrm{CD} 4^{+}$Fas-R $\left(\mathrm{CD} 95^{+}\right)$cells. Example scattergram of $\mathrm{CD}^{+}$cells stained with anti-ICE and CD95 mAb. Lymphocytes from HIV-1infected patients were stained with CD4-CyPE, anti-ICE-FITC, and CD95-PE. Scattergrams include CD4+ lymphocytes only. After gating on $\mathrm{CD}^{+}$cells, CD95-PE $\log$ fluorescence activity was displayed versus anti-ICE-FITC log fluorescence activity.

Multiple ICE-related proteases have been described in mammalian cells $(21,23-25)$. Although precursors of these cysteine proteases are found in most nucleated cells, they are not active until they are cleaved at their aspartate residues and assembled into heterodimers. The activation cascades resulting in the conversion of caspases into their active forms are initiated by cross-linking of cytokine receptors such as Fas-R or TNF-R1. Transduction pathways for the various apoptotic signals are most likely interrelated, but their effects may vary with the cell type and the transducing cytokine. Inhibition of apoptosis in $\mathrm{CD}^{+}$cells has been demonstrated recently using a specific ICE inhibitor, while apoptosis of $\mathrm{CD}^{+}$lymphocytes was inhibited by an inhibitor of CPP32, an ICE-related protease (18). These findings suggest that CPP32 is the predominant ICE-like protease controlling apoptosis in $\mathrm{CD}^{+}$cells. Unlike ICE, which triggers apoptosis easily in mammalian cells, CPP32 causes apoptosis only at high concentrations (23). In agreement with these results, we have demonstrated that the active and apoptosis-mediating forms of ICE were present predominantly in $\mathrm{CD}^{+}$rather than $\mathrm{CD}^{+}$lymphocytes. The constant presence of active forms of ICE in $\mathrm{CD} 4^{+}$cells may account for their greater sensitivity to Fas-mediated apoptosis and explain the predominant depletion of CD4 ${ }^{+}$cells in HIV-1 infection. However, the relationship of ICE-related proteases $(24,26,27)$ to the apoptotic process has yet to be elucidated completely. Many ICE-related proteases are capable of selfactivation, whereas some are activated by other ICE-related proteases $(12,24)$. For example, ICE (caspase-1) can activate itself as well as CPP32 (caspase-3). While CPP32 is an important intermediate in granzyme B-mediated apoptosis $(20,28)$, ICE appears to play no role in this process.

Expression of ICE protein and Fas-mediated apoptosis in lymphocytes from AIDS patients appears to be independent of the presence of HIV-1 in the affected cells, since only a minimal proportion of circulating lymphocytes (PBL) are infected with HIV, but Fas and its membrane-bound ligand are elevated on $30-60 \%$ of PBLs $(5,6)$. It is likely that both Fas-R expression and activation result from secondary immunological mechanisms occurring in the course of HIV-1 infection. Upregulation of Fas-R expression is associated with TNF- $\alpha$ and 
Normal

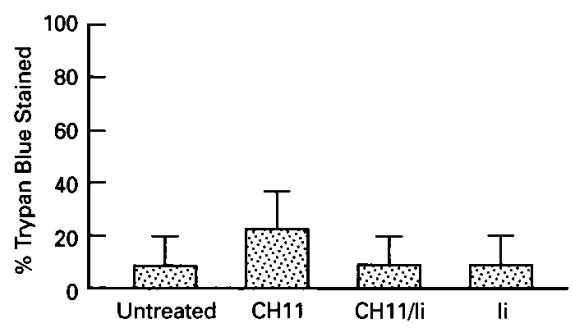

Normal

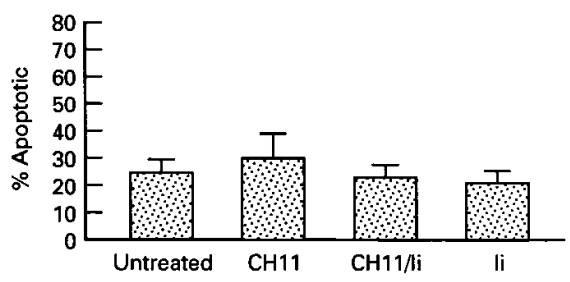

Patient

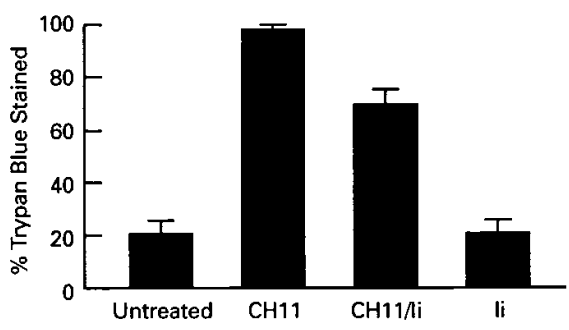

Patient

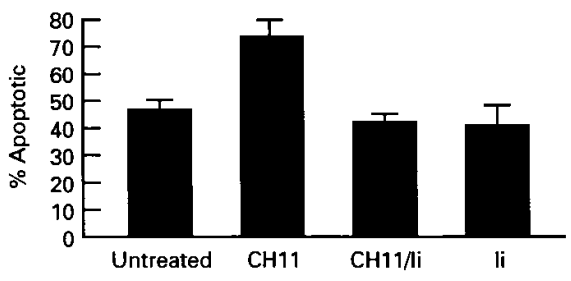

Figure 9. Inhibition of spontaneous and Fas-mediated apoptosis in cultures of lymphocytes derived from patients with HIV-1 infection using ICE inhibitor (Ii). Control (Untreated) and PBMC from HIV-1infected patients treated with Fas agonist (CH11) were cultured in the presence of ICE-inhibitor for $2 \mathrm{~d}$ and stained with annexin to detect apoptosis. Bars, Percentage of viable cells (top) or cells undergoing apoptosis in cultures (bottom; $P<0.01$ for control vs. CH11-treated cells; $P<0.01$ for CH11-treated vs. ICE inhibitor/CH11treated cells).
IFN- $\gamma$ stimulation, cytokines that are produced abundantly in HIV-1 infection (29-31). We have reported previously increases in Fas-L both in the serum of HIV-1-infected patients and in the supernatants derived from lymphocyte cultures (5). In addition, TNF- $\alpha$ and IFN- $\gamma$ have been shown to enhance Fas-R expression on a variety of hematopoietic cells (16).

Apoptosis, as a natural means of controlling viral infection, was described initially for baculovirus $(32,33)$. This mechanism can result in premature death of virus-infected cells. We have demonstrated previously that Fas-R triggering (5) was associated with significant decreases in $\mathrm{p} 24$ production adjusted for the viable cell numbers, but were unable to study adequately the effect of ICE in this investigation, as p24 production was low or undetectable in all patients studied-an observation that may be related to treatment with antiviral agents. Recently, the effect of ICE inhibitors on HIV replication was studied by another group of investigators, who found that ICE inhibitors increased HIV replication (34).

In conclusion, the differential expression of ICE in $\mathrm{CD} 4^{+}$ cells of HIV-infected patients may explain the increased susceptibility to apoptosis and eventual depletion of these cells during the progression of the disease. Our results may have implications for future therapy of AIDS, and specific response to ICE inhibitors could potentially be used to develop new treatment strategies.

\section{References}

1. Oyaizu, N., and S. Pahwa. 1995. Role of apoptosis in HIV pathogenesis. J. Clin. Immunol. 15:217-231.

2. Groux, H., G. Torpier, D. Monte, Y. Mouton, A. Capron, and J.C. Ameisen. 1992. Activation-induced death by apoptosis in $\mathrm{CD}^{+} \mathrm{T}$ cells from human immunodeficiency virus-infected asymptomatic individuals. J. Exp. Med. 175:331-340.

3. Terai, C., R.S. Kornbluth, C.D. Pauza, D.D. Richman, and D.A. Carson. 1991. Apoptosis as a mechanism of cell death in cultured T lymphoblasts acutely infected with HIV-1. J. Clin. Invest. 87:1710-1715.

4. Meyaard, L., S.A. Otto, R.R. Jonker, M.J. Mijnster, R.P.M. Keet, and F. Miedema. 1992. Programmed death of T cells in HIV-1 infection. Science. 257: $217-219$

5. Sloand, E.M., N.S. Young, P. Kumar, F.F. Weichold, T. Sato, and J.P.
Maciejewski. 1997. Role of Fas ligand and receptor in the mechanism of T-cell depletion in acquired immunodeficiency syndrome: effect on $\mathrm{CD}^{+}$lymphocyte depletion and human immunodeficiency virus replication. Blood. 89:1357-1363.

6. Debatin, K.M., A. Fahrig-Faissner, S. Enenkel-Stoodt, W. Kreuz, A. Benner, and P.H. Krammer. 1994. High expression of APO-1 (CD95) on T lymphocytes from human immunodeficiency virus-1-infected children. Blood. 83: 3101-3103.

7. Katsikis, P.D., E.S. Wunderlich, C.A. Smith, L.A. Herzenberg, and L.A. Herzenberg. 1995. Fas antigen stimulation induces marked apoptosis of T lymphocytes in human immunodeficiency virus-infected individuals. J. Exp. Med. 181:2029-2036.

8. Los, M., M. Van de Craen, L.C. Penning, H. Schenk, M. Westendorp, P.A. Baeuerle, W. Droge, P.H. Krammer, W. Fiers, and K. Schulze-Osthoff. 1995. Requirement of an ICE/CED-3 protease for Fas/APO-1-mediated apoptosis. Nature. $375: 81-83$.

9. Alderson, M.R., T.W. Tough, T. Davis-Smith, S. Braddy, B. Falk, K.A. Schooley, R.G. Goodwin, C.A. Smith, F. Ramsdell, and D.H. Lynch. 1995. Fas ligand mediates activation-induced cell death in human T lymphocytes. J. Exp. Med. 181:71-77.

10. Enari, M., H. Hug, and S. Nagata. 1995. Involvement of an ICE-like protease in Fas-mediated apoptosis. Nature. 375:78-81.

11. Kuida, K., J.A. Lippke, G. Ku, M.W. Harding, D.J. Livingston, M.S.S. $\mathrm{Su}$, and R.A. Flavell. 1995. Altered cytokine export and apoptosis in mice deficient in interleukin-1 beta converting enzyme. Science. 267:2000-2003.

12. Tewari, M., L.T. Quan, K. O'Rourke, S. Desnoyers, Z. Zeng, D.R. Beidler, G.G. Poirier, G.S. Salvesen, and V.M. Dixit. 1995. Yama/CPP32 beta, a mammalian homolog of CED-3, is a CrmA-inhibitable protease that cleaves the death substrate poly(ADP-ribose) polymerase. Cell. 81:801-809.

13. Mashima, T., M. Naito, N. Fujita, K. Noguchi, and T. Tsuruo. 1995 Identification of actin as a substrate of ICE and an ICE-like protease and involvement of an ICE-like protease but not ICE in VP-16-induced U937 apoptosis. Biochem. Biophys. Res. Commun. 217:1185-1192.

14. Nicholson, D.W., A. Ali, N.A. Thornberry, J.P. Vaillancourt, C.K. Ding, M. Gallant, Y. Gareau, P.R. Griffin, M. Labelle, Y.A. Lazebnik, et al. 1995. Identification and inhibition of the ICE/CED-3 protease necessary for mammalian apoptosis. Nature. 376:37-43.

15. Lazebnik, Y.A., S.H. Kaufmann, S. Desnoyers, G.G. Poirier, and W.C. Earnshaw. 1994. Cleavage of poly(ADP-ribose) polymerase by a proteinase with properties like ICE. Nature. 371:346-347.

16. Maciejewski, J., C. Selleri, S. Anderson, and N.S. Young. 1995. Fas antigen expression on $\mathrm{CD} 34^{+}$human marrow cells is induced by interferon $\gamma$ and tumor necrosis factor $\alpha$ and potentiates cytokine-mediated hematopoietic suppression in vitro. Blood. 85:3183-3190.

17. Selleri, C., T. Sato, L. del Vecchio, L. Luciano, A.J. Barrett, B. Rotoli, N.S. Young, and J.P. Maciejewski. 1997. Involvement of Fas-mediated apoptosis in the inhibitory effects of interferon- $\alpha$ in chronic myelogenous leukemia. Blood. 89:957-964.

18. Estaquier, J., M. Tanaka, T. Suda, S. Nagata, P. Golstein, and J.C. Ameisen. 1996. Fas-mediated apoptosis of $\mathrm{CD}^{+}$and $\mathrm{CD} 8^{+} \mathrm{T}$ cells from human immunodeficiency virus-infected persons: differential in vitro preventive effect 
of cytokines and protease antagonists. Blood. 87:4959-4966.

19. Sander, B., J. Andersson, and U. Andersson. 1991. Assessment of cytokines by immunofluorescence and the paraformaldehyde-saponin procedure. Immunol. Rev. 119:65-93.

20. Martin, S.J., G.P. Amarante-Mendes, L. Shi, T.H. Chuang, C.A. Casiano, G.A. O'Brien, P. Fitzgerald, E.M. Tan, G.M. Bokoch, A.H. Greenberg, and D.R. Green. 1996. The cytotoxic cell protease granzyme B initiates apoptosis in a cell-free system by proteolytic processing and activation of the ICE/ CED-3 family protease, CPP32, via a novel two-step mechanism. EMBO (Eur. Mol. Biol. Organ.) J. 15:2407-2416.

21. Kumar, S., and N.L. Harvey. 1995. Role of multiple cellular proteases in the execution of programmed cell death. FEBS (Fed. Eur. Biochem. Soc.) Lett. 375:169-173.

22. Naito, M., K. Nagashima, T. Mashima, and T. Tsuruo. 1997. Phosphatidylserine externalization is a downstream event of interleukin-1 beta-converting enzyme family protease activation during apoptosis. Blood. 89:2060-2066.

23. Fernandes-Alnemri, T., G. Litwack, and E.S. Alnemri. 1994. CPP32, a novel human apoptotic protein with homology to Caenorhabditis elegans cell death protein Ced-3 and mammalian interleukin-1 beta-converting enzyme. $J$. Biol. Chem. 269:30761-30764.

24. Faucheu, C., A. Diu, A.W.E. Chan, A.M. Blanchet, C. Miossec, F. Herve, V. Collard-Dutilleul, Y. Gu, R.A. Aldape, J.A. Lippke, et al. 1995. A novel human protease similar to the interleukin-1 beta converting enzyme induces apoptosis in transfected cells. EMBO (Eur. Mol. Biol. Organ.) J. 14: 1914-1922.

25. Munday, N.A., J.P. Vaillancourt, A. Ali, F.J. Casano, D.K. Miller, S.M. Molineaux, T.T. Yamin, V.L. Yu, and D.W. Nicholson. 1995. Molecular cloning and pro-apoptotic activity of $\mathrm{ICE}_{\text {rel }} \mathrm{II}$ and $\mathrm{ICE}_{\text {rel }} \mathrm{III}$, members of the ICE/CED-3 family of cysteine proteases. J. Biol. Chem. 270:15870-15876.

26. Cerretti, D.P, C.J. Kozlosky, B. Mosley, N. Nelson, K. Van Ness, T.A.
Greenstreet, C.J. March, S.R. Kronheim, T. Druck, L.A. Cannizzaro, et al. 1992. Molecular cloning of the interluekin-1 beta converting enzyme. Science. 256:97-100.

27. Miller, B.E., P.A. Krasney, D.M. Gauvin, K.B. Holbrook, D.J. Koonz, R.V. Abruzzese, R.E. Miller, K.A. Pagani, R.E. Dolle, M.A. Ator, and S.C. Gilman. 1995. Inhibition of mature IL-1 beta production in murine macrophages and a murine model of inflammation by WIN 67694, an inhibitor of IL-1 beta converting enzyme. J. Immunol. 154:1331-1338.

28. Lippke, J.A., Y. Gu, C. Sarnecki, P.R. Caron, and M.S.S. Su. 1996. Identification and characterization of CPP32/Mch2 homolog 1, a novel cysteine protease similar to CPP32. J. Biol. Chem. 271:1825-1828.

29. Brunner, T., R.J. Mogil, D. LaFace, N.J. Yoo, A. Mahboubl, F. Echeverri, S.J. Martin, W.R. Force, D.H. Lynch, C.F. Ware, and D.R. Green. 1995 Cell-autonomous Fas (CD95)/Fas-ligand interaction mediates activation-induced apoptosis in T-cell hybridomas. Nature. 373:441-444.

30. Piasecki, E., T.K. Ledwon, A.D. Inglot, B. Knysz, K. Simon, M. Inglot, and A. Gladysz. 1994. Interferon and tumor necrosis factor responses of HIV+ patients as markers for monitoring of the AIDS progression. Arch. Immunol. Ther. Exp. (Warsz.). 42:439-445.

31. Dhawan, S., A. Heredia, L.M. Wahl, J.S. Epstein, M.S. Meltzer, and I.K Hewlett. 1995. Interferon- $\gamma$-induced downregulation of CD4 inhibits the entry of human immunodeficiency virus type-1 in primary monocytes. Pathobiology. 63:93-99.

32. Clouston, W.M., and J.F.R. Kerr. 1985. Apoptosis, lymphocytotoxicity and the containment of viral infections. Med. Hypotheses. 18:399-404

33. Clem, R.J., and L.K. Miller. 1993. Apoptosis reduces both the in vitro replication and the in vivo infectivity of a baculovirus. J. Virol. 67:3730-3738.

34. Chinnaiyan, A.M., C. Woffendin, V.M. Dixit, and G.J. Nabel. 1997. The inhibition of pro-apoptotic ICE-like proteases enhances HIV replication. Nat. Med. 3:333-337. 